\title{
Kitap Değerlendirmesi
}

\section{Felsefe ve Tasavouf \\ Yazar: Levent Bayraktar}

(Aktif Düşünce Yayıncılık, Ankara 2016)

\section{Fatma Sinem Avcılar}

Ankara Yıldırım Beyazıt Üniversite'sinde çalışmalarını sürdürmekte olan Prof. Dr. Levent Bayraktar'ın "Felsefe ve Tasavvuf" başlıklı çalışması daha önce değişik vesilelerle ele alınmış olan makale, bildiri ve mülakatlardan oluşmaktadır. Yazar, kitapta yer alan metinlerin gayesini, kültür ve medeniyetimizin temel kurumlarından olan tasavvuf ve onun ekseninde oluşan değerleri irdelemek niyeti ve gayreti olarak ifade etmektedir. Bu bağlamda Mevlana, Yunus Emre gibi mutasavvıflar; Camus, Bergson gibi filozoflarla birlikte değerlendirilmektedir. Böyle bir karşılaştırmalı ele alışın yanı sıra; tasavvufun güncel sorunlara verebileceği cevapların bugün için bir kaynak ve ufuk olarak değerlendirilmesi hususunda denemeler bulunmaktadır. Mutasavvifların eskimeyen bir dünya görüşüne sahip oldukları, tasavvufi tefekkürün dünya sorunlarına her dem taze bir cevap olduğu tezi okuyucunun dikkatine sunulmaktadır.

\footnotetext{
*Yüksek Lisans Öğrencisi, İzmir Katip Çelebi Üniversitesi, Felsefe Bölümü, ftmsnm@hotmail.com

Bu makale iThenticate sistemi tarafından taranmıştır.

Makale Gönderim Tarihi: 1 Haziran 2019
} 
"Felsefe ve Tasavvuf" başlıklı eser, "Ölümden Öğrenmek”, “Çă̆daş Türk Düşüncesinin Önünde Bir Kaynak ve Ufuk: Yunus Emre", "Dünya Sorunlarına Her Dem Taze Bir Cevap: Yunus Emre", "Her Dem Yunus Emre", "Yunus'un Güncelliği", "Yunus'un Değer Metafiziğine Bir Giriş Denemesi", "Albert Camus ve Yunus Emre'de Absürd Kavramı", "Berlin Yunus Emre Günlerinin Ardından", "Mevlana'da Ruh-Beden İlişkisi Problemi", "Mevlana ve Bergson'da Ruh Kavrami", "Ahmed Yesevi ve Felsefi Mirası Üzerine”, "Ken'an Rifai Büyükaksoy'un İlim ve İrfan Anlayışı”, "Ahilik ve Ahlak", "Felsefe ve Tasavvuf Üzerine", "Edebiyat, Hikmet ve Evrensellik Üzerine" ve son olarak "Birleyerek Oluşmak Üzerine" başlıklı on altı bölümden oluşmaktadır.

“Ölümden Öğrenmek” başlıklı birinci kısımda yazar, insanoğlunun kendi varoluşunu temellendirmek isteyenbir varlık olduğu vurgusu üzerinde durmaktadır. Bu doğrultuda insan, inşa ettiği varoluşu bağlamında bir hayat yaşamaktadır. Çünkü; insan bilinç, hafıza ve şahsiyet varlığıdır. Bununla birlikte insanın sınırlı ve sonlu bir varlık olduğunun idraki içinde kendisini temellendirmek zorunda oluşu, onun en büyük öğreticisi olarak kabul görmektedir. Bu noktada öğrenebilmek, var olabilmek için ön koşul olmaktadır. Yazara göre, insanoğlu tabiattaki diğer canl1lardan özne ve şahsiyet varlığı olmaklığı bakımından ayrılmaktadır. Bu noktada özne olabilmek, özümüzü inşa edebilmekle mümkün olacaktır. Buradan hareketle, her insanın kendi özünü ve şahsiyetini kendisinin oluşturması gerektiği hususu vurgulanmaktadır.

Bununla birlikte, bölümde ölümden öğrenmenin mümkün olup olmadığ1 konusu da irdelenmektedir. Şayet ölümden öğrenmek mümkün ise ölümden ne öğrenilebileceği sorusu esas oluşturmaktadır. Bu doğrultuda yazar, ölümün ölümden öğrenebilenlere bir varoluş imkanı açmakta olduğunu ileri sürmektedir. İnsanın ölümlülüğü, faniliğini idrak etmesi, kişisel sürekliliği ve şahsiyeti açısından da bir inşa edici değer olarak belirtilmektedir. Burada bahsi geçen fanilik bilincinin insana her şeyin bir emanet olduğunu kavramasına imkan sunduğu ifade edilmektedir. Bu vesile ile ölümden insanın öğrendiği en temel erdem ya da hakikat, insanın 
gücü yettiği oranda kibre kapılmadan hakikat yolcusu olmasıdır. Yazar, insana yakışan şeyin, varoluş endişesi ve gayreti içerisinde bulunup, bununla birlikte tevazu sahibi olmak olduğu hususuna dikkat çekmektedir. İnsan, var olan fiziki dünya içinde kendisine etik ve manevi bir dünya inşa etmektedir. Bu insan, kendisini gerçekleştirmiş ve özne varlığa dönüşmüş bir şahsiyettir. Buradan hareketle, ancak sınırlı bir varlık olduğunun farkında olan bir insan kendisini gerçekleştirebilir. Bu noktada yazar, sınırlı ve sonlu olma şuurunun insana haddini bildirdiği vurgusunu yapmaktadır. Son olarak bu bölümde yazar, Bergsoncu hafıza ve benlik kuramına temas etmektedir. Bergsoncu kurama göre insan, sinırlı ve sonlu beden hayatı içerisinde hafıza, bilinç, irade ve muhayyile yetileri ile burada ve şimdi ile kayıtlı bir varoluşa mahkum olmaktan çıkmaktadır. Burada insanın diğer canlılardan farklı olarak zamanı üç boyutlu yaşayan ve idrak eden yegane varlık olduğu hususu üzerinde durulmaktadır. Bu doğrultuda insan burada ve şimdi giriştiği her tutum ve davranışta hafıza sayesinde bütün geçmişi ile bulunmaktave eylemektedir. Bununla birlikte insan, bir gelecek tasavvuruna da sahip olan bir varlıktır. Bu demektir ki insan zamanı bir bütün ve oluş halinde tasavvur etmek durumundadır. Son aşamada bu tasavvurun metafizik bir hamle ile insanın doğumdan öncesi ve ölümden sonrasını da hatırda tutmasını zorunlu kıldığı vurgusu yapılmaktadır.

“Çağdaş Türk Düşüncesinin Önünde Bir Kaynak ve Ufuk: Yunus Emre" başlıklı ikinci bölümde yazar, Türk düşüncesinin kabaca son iki yüz yılında Batı etkisi altında olduğu kanaatindedir. Bu durumun daha sağlıklı bir neticeyle sonuçlanması için gelenekli olan ile yeni veya yabancı olanın iletişim ve etkileşim çerçevesinde bir süreç izlemesi gerektiğini savunmaktadır. Günümüz Türk Düşüncesinin en temel sorunlarından birisini, kendi gündemini kendisinin belirleyemiyor olması olarak saptamaktadır. Yazar, sorunun zaman içerisinde giderilememesi, başka bir deyimle ölçünün kaçırılması halinde taklitçilik ve yabancılaşmanın kaçınılmaz olacağı tespitine varmaktadır. Gelenekli başarılar elde edebilmek için ise kültürel ve entelektüel ortam yaratmak ve her alanda geleneğin tevarüs edilmesi bir çözüm yolu olarak sunulmaktadır. 
Bu bağlamda Çağdaş Türk düşüncesinin, Yunus Emre ile irtibata geçmesinin büyük bir katkı sağlayabileceği tezi ortaya konmaktadır. Felsefenin ve metafiziğin ebedi problemlerinden olan "birlik ve çokluk", "görünüş ve gerçeklik" meselelerine Yunus Emre ile açıklık getirilmektedir. Yunus Emre, çokluğun yanıltıcılığı ve görünüşün gerçekliği maskelediğini ifade etmektedir. Bu da insanın ve toplumun çıkmazı olan gönül daralmasını kaçınılmaz hale getirmektedir. Yazara göre, bahsi geçen gönül daralmasına tedavi olacak olan pusula gönlün kendisidir. Gönül ile görmek, duymak ve düşünmek insanı metafizik ve ulvi bir varlık haline getirmektedir. Buna ek olarak gerçek hümanizmanın insana insan olduğu için değer vermek ve saygı duymak olduğu ifade edilmektedir.

"Dünya Sorunlarına Her Dem Taze Bir Cevap: Yunus Emre" başlıklı üçüncü bölümde yer alan bildirinin temel şeması, öncelikle insan-dünya ilişkisi, dünya sorunları ve bunlara nasıl çözüm yolu bulunabilir gibi problemlerin irdelenmesi gayreti ekseninde şekillenmektedir. Ardından, Yunus Emre'nin düşünce ve değer dünyasının entelektüel ve etik meseleleri ele alınmaya çalışılmaktadır. Bu bölümde yazar, Yunus Emre vesilesi ile insanımıza ve bütün insanlığa, barış ve selamet içerisinde nasıl yaşanılabileceğinin anahtarını sunmaktadır. İnsanoğlunun "insan, insanın kurdudur" diye tanımlanması ve betimlenmesi, çağımızda artan savaşlar, yoksulluk vb. sorunlar dünyayı daha tekinsiz bir yere dönüştürmüş ve dönüştürmeye devam etmektedir. İçinde bulunduğumuz dünyayı daha yaşanabilir bir hale getirmek insan olmakla alakalıdır. Zira insan olmak bir süreç ve tekamül işidir. Yazar, bu hususa açıklık getirmek için Yunus Emre'nin ten ve can ayrımını dile getirmektedir. Can, dünyevi bir varlık değildir ve Yunus için maddi dünya ile bedenin asıl gerçeklik olması söz konusu olamaz. Bu doğrultuda insanın en büyük uyanışı faniliğini, sonluluğunu, sınırlılığını fark etmesiyle gerçekleşecektir.

"Her Dem Yunus Emre" başlıklı dördüncü bölümde yazar, Yunus Emre'nin dilinden insanlığa bir çıkış kapısı aralamaktadır. Burada insan, kendi içindeki "gevher"in farkında olmaya davet edilmektedir. İnsanı kendine, tabiatına ve yaratılışına yabancılaştıran başlıca duygular kin, intikam, haset ve bencillik olarak tespit edil- 
mektedir. Bu tuzağa düşmemek için ise affetme ve iyiyi dilemek öğütlenmektedir.

“Yunus'un Güncelliği” başlıklı beşinci bölüm, Yunus'u güncel olarak değerlendirmek nasıl mümkündür? sorusu ekseninde şekillenmektedir. Bu soruya cevap niteliğinde ise Yunus Emre'nin tarihin belirli bir diliminde ve coğrafyasında yaşamış olmasına rağmen bütün zamanlar ve bütün mekanlar için anlamlı ve değerli bir tefekkür ortaya koymuş olduğu ifade edilmektedir. Bu ifadenin temelini oluşturan zemin ise Yunus'un dile getirmiş olduğu hikmetin sahihliğinden kaynaklanmaktadır. Bu hikmet, manevi ve semavi kaynaklıdır. İlhamını Kur'an metafiziğinden ve ahlakından almaktadır. Böylece bu tefekkür manevi ve ilahi bir boyut taşımaktadır. Yazar, sınırlı ve sonlu bir dünya içinde insanın kendisini reşit bir birey olarak gerçekleştirmesi gerektiği üzerinde durmaktadır. Reşit olmak ise farkındalık ve sorumluluk ile temellendirilmektedir. Bu farkındalık bilinçlenmeyi, bilinçlenmek ise bilmeyi beraberinde getirmektedir. Yazarın ifadesiyle bilmek ise olmak için bir hareket noktasıdır.

"Yunus'un Değer Metafiziğine Bir Giriş Denemesi" başlıklı altıncı bölümde yazar, Yunus'un kendisine yöneltmiş olduğu "sen bu dünyaya niye geldin" sorusuyla, asıl sorunun "nasıl" değil, "niçin" olduğunun vurgusu yapılmaktadır. Beraberinde "nasıl" sorusunun insanı fizik dünyaya, "niçin" sorusunun ise fizik ötesine yönelttiğini, meselenin özüne ise "niçin" sorusunu sormakla ulaşılabileceğini ifade etmektedir. Yazara göre, niçin sorusunun cevaplandırılması varlığı ve insanı anlamlandırma ve bir değer metafiziği ortaya koyma girişimidir. Yazarın ifadesiyle Yunus'un keşfettiği temel hususlardan biri de insanın kendi içine dönmesi ve kendisini bilmesi gerekliliğidir. Bu doğrultuda insanın evreni bilmesi ve tanıması ilim ise, kendisini tanıması bir çeşit irfan ve ilim ile irfanı birlemesi de bilgelik olarak tezahür eder şeklindeki ifadesi yerinde bir tespittir. Sürekli akış halinde olan dünya içerisinde insan, bilmekten olma mertebesine geçmek durumunda olan bir varlıktır. Çünkü, insan sadece bilen bir varlık değil, aynı zamanda seven, inanan ve değerlerin sesini duyan bir varlıktır. Yunus Emre için değerler, asıl gerçekliklerdir ve varlıklarını ila- 
hi nizamdan almaktadırlar. Bu noktada insan için esas olan, bu dünya hayatında hakkı ve hakikati bulabilmektir. Zira insan, yeryüzünde Tanrının halifesidir. Bununla birlikte Yunus Emre için mesele, varlığın, insanın, bilginin ve değerlerin kaynağının birlenmesi ile çözülebilir.

"Albert Camus ve Yunus Emre' de Absürd Kavramı" başlıklı yedinci bölümün içeriği, A. Camus ve Yunus Emre'deki "absürd" kavramı olarak belirlenmektedir. Bölüm, her iki düşünürün sistemlerindeki bazı ortak noktaları ve ayrılıkları saptama gayesini barındırmaktadır. Yazar, bu iki düşünürü birlikte ele alma sebebini, onların varoluşçu felsefe içinde değerlendirilebilecek olmaları ve bu felsefenin kavramlarını, çoğu zaman aynı anlamları yüklemeseler de, kullanıyor olmaları olarak ifade etmektedir. Yunus'a göre, her şeyin özü Aşk’tır. Yunus Emre için gerçek aşk, İlahi aşktır. Camus'de ise, Tanrı'ya bir başkaldırma vardır. Tanrıyı kendi içinde yargılamaktadır. Çünkü, Tanrı insanı ölüme mahkum bırakmıştır. Böyle bir Tanrı saçmadır. Burada yazar, "Tanrı ile ilgili olarak başkaldırma problemi, var olan bir Tanrı'yı gerektirir" ifadesiyle meseleyi anlamlı bir boyuta taşımaktadır. Yunus'a göre, gerçekten var olan Tanrı'dır ve bütün diğer şeyler varlığını ve anlamını ondan almaktadır. Albert Camus ise Tanrı'nın olmadı̆̆ı, dünyanın ve hayatın saçma olduğu düşüncesinden hareketle bir saçma ahlakından, başkaldırı ahlakı çıkarmaya çalışan bir filozof olarak karşımıza çıkmaktadır. Bu düzlemden hareketle Camus, Tanrısız evrende saçmaya rağmen ve saçma içerisinde insanın başkaldırısını insanlık adına bir çıkış olarak ortaya koyarken; Yunus, varlığı görünüş ve gerçeklik olarak ayırt edip, görünüşe takılı kalmayarak, insan için çıkış yolunun mutlak varlığa yönelmek ve insanlıktan, insan-1 kamilliğge doğru yükselmek ideali olarak sunmaktadır.

"Berlin Yunus Emre Günlerinin Ardından" başlıklı sekizinci bölümde, Yunus ile Batı arasındaki söylem ve anlam farklılıkları üzerinden ilerlenmektedir. Temelini Yunus Emre' nin oluşturduğu ve Yunus Emre'yle birlikte Bacon, Kant, Sartre, Camus ve Heidegger gibi filozoflara da değinerek bir değer çizgisi inşa etmeye gayret edilmektedir. 
"Mevlana'da Ruh-Beden İlişkisi Problemi" başlıklı dokuzuncu bölüm, Mevlana'nın inşa etmiş olduğu sisteminden hareketle oluşturulmaktadır. Bu sistemde insan bir "ruh" ve "beden" varlığ1 olarak karşımıza çıkmaktadır. İnsan ruh varlığı olarak nurdan yaratılmıştır. Fakat öte yandan toprak ve çamurdan olma bir beden içerisine hapsedilmiştir. Bu düşünce doğrultusunda insan, zıt unsurların birleşiminden meydana gelmiş olmak bakımından bir gerilim içerisindedir. Var olan gerilimden hareketle Mevlana düşüncesinde, insan varlığında asli unsurun ruh olduğu ifade edilmektedir. Ruh, maddi, nebati ve hayvani merhalelerden geçerek, insani ruh seviyesinde akıl, bilinç ve aşk varlığı olarak insanı ortaya koymaktadır. Ancak bu şekilde insan-1 kamil olma yolunda ilerlemek mümkün olacaktır.

"Mevlana ve Bergson'da Ruh Kavramı" başlıklı onuncu bölümde yer alan bildiride hayat, ruh, madde, tekamül, yenilik ve dinamizm gibi ortak kavram ve kategorilerden hareketle Mevlana ve Bergson ele alınmaktadır. Bu bölüm bir mutasavvıf ve mütefekkir ile bir filozofu ruh kavramı ve kavrayışı ekseninde ele alıp, karşılaştırma mahiyetini içermektedir.

“Ahmed Yesevi ve Felsefi Mirası Üzerine" başlıklı on birinci bölüm "hikmet" kavramı temelinde kaleme alınmaktadır. Bu bölüm, Hoca Ahmed Yesevi'nin hikmet kavramindan hareketle, insanın kendisini içinde bulunduğu kaostan nasıl kurtarabileceği ve akabinde kişinin kendisini nasıl inşa etmesi gerektiği hususunu ele almaktadır. Ahmed Yesevi düşüncesinde, insanın "hikmet"e yönelebilmesi için gerekli pusula insanın içinde taşıdığı cevher olarak nitelendirilmektedir. Bu da farkındalık gerektirmektedir. İnsanda var olan cevherin fark edilmesi, insanın kendisini bilmesi ve inşa etmesi yolunda ona bir çıkışyolu sunmaktadır.

“Ken'an Rifai Büyükaksoy'un İlim ve İrfan Anlayışı" başlıklı on ikinci bölümde yer alan bildiri, 20.yüzyılın, insanlığın gelmiş olduğu bir bilgi ve bilim çağı olmasına rağmen, maddi ve teknik sahadaki gelişmenin insani ve medeniyet sahasında buna paralel bir şekilde gitmediği tespitinden hareketle inşa edilmektedir. Var olan medeniyetlerin hem maddi hem de manevi anlamda buhran içinde oldukları ifade edilmektedir. Büyükaksoy, bu buhran- 
dan çıkış için alternatif bir medeniyet projesi ortaya koymaktadır. Büyükaksoy'un sergilediği ve tedris ettiği ilim, irfan, iman, edep, ahlak, hikmet, adalet, feragat, sadakat, vefa, dostluk, irşat kavram ve ilkelerine dayalı insan yetiştirme sistemi, bugün içinde anlamlı ve değerli, gerçekleştirilebilir bir medeniyet tasavvuru sunmaktadır.

"Ahilik ve Ahlak" başlıklı on üçüncü bölümde yer almakta olan bildiri, Ahilik kurumunun esas mahiyeti ve bu mahiyetin ahlak alanıyla harmanlanarak yeni bir bakış açısı kazandırma gayreti temelinde oluşmaktadır. Buradan hareketle Ahilik, bir meslek örgütü olmaktan ziyade, yazarın deyimiyle bir insanlık mektebi halini almaktadır. Bu doğrultuda Ahiliğin özü ve esası, edep, fazilet ve ahlaktır. Bu noktada insan bir değer varlığı olarak karşımıza çıkmaktadır.

"Felsefe ve Tasavvuf Üzerine" başlıklı on dördüncü bölüm, felsefe nedir?, felsefe ile din kavramı aynı terazide değerlendirilebilir mi?, insanın kemale yolculuğu sırasında felsefenin rolü nedir?, tasavvufta kemale erme sürecinde temele alınan "aşk" kavramının felsefedeki yeri nedir? gibi sorulara cevap mahiyetini taşırken, aynı zamanda insanı bilen bir özne olarak, bilinçlenmeye ve bununla birlikte bir değer varlığı olarak kendisini inşa etmesine davet oluşturmaktadır.

“Edebiyat, Hikmet ve Evrensellik Üzerine" başlıklı on beşinci bölümde, Türk edebiyatı ve Türk düşüncesi arasında bir münasebet kurulabilir mi?, edebiyat bir tefekkür alanı mıdır? sorularından hareketle edebiyat ile hikmet ve hakikat arasinda, dolayısıyla edebiyat ve felsefe arasında sıkı bir bağ ve ilişkinin olduğu zemini oluşturulmaktadır. Bununla birlikte felsefe ve düşünce hayatımızda Türk edebiyatından ne kadar istifade edebileceğimiz problemi üzerinde durulmaktadır.

“Birleyerek Oluşmak Üzerine" başlıklı on altıncı bölüm, her şeyin baş döndürücü hızla değiştiği bu çağda, insanoğlunun kendisini yalnız ve pusulasız hissettiği ve her anlamda bunalım yaşadığ probleminden yola çıkarak oluşturulmaktadır. İnsanoğlunun günümüzde yaşadığı temel sorunun ve bunalımın, maddi ve teknik 
sahadaki yetersizlikten değil, insani alan yani değerler alanındaki krizden kaynaklandığı ifade edilmektedir. Bu doğrultuda insanoğlunun özne olmaklığına dair çeşitli sıkıntı ve buhranlarına bir çözüm ve çıkış yolu sunmakta olan, aynı zamanda bu bölümde muhtevası irdelenen "Birleyerek Oluşmak" başlıklı eser, okuyucu için burada bir anahtar mahiyeti ve gayesi taşımaktadır.

Sonuç olarak insan, sürekli akış halinde olan bir dünya içerisinde kendisini ve varoluşunu temellendirmek zorunda olan bir varlık olarak karşımıza çıkmaktadır. Bu temellendirme yolunda insanın pusulasız kalmaması, ancak kendisini bir şahsiyet varlığı olarak inşa etmesine bağlı kalmaktadır. Kendisini bir şahsiyet varlığı olarak inşa edebilen insan, içsel bir öz farkındalık mertebesine ulaşmaktadır. Bergsoncu kuramdan hareketle, insanın hafıza, bilinç, irade ve muhayyile yetilerine sahip bir varlık olması, onun diğer canlılardan farklı olarak zamanı üç boyutlu yaşayan ve idrak eden yegane varlık olduğunu göstermektedir. Bununla birlikte insan bedensel bir varlık olmasiyla beraber aynı zamanda ruhsal bir varlıktır. Buda insanı bir değer varlığı haline getirmektedir. Ancak değer varlığı olabilmek, zihinsel bir dönüşüm gerektirmektedir. Bu doğrultuda insan kendisini etik ve manevi bir dünya içerisinde idrak ve inşa etmek durumundadır. Kişi kendi kökleri ile bağını koparmadan, geleceği inşa edebilen bir düşünce sistemi oluşturmalıdır. Bu noktada insanın kendisini aynı zamanda kendisi olmayan üzerinden de idrak etmesi gerekmektedir. Son olarak, felsefe ile bütünleşen bir tasavvuf anlayışına ihtiyaç bulunmaktadır. Tasavvuf, fert temelinde yaşanan dini tecrübeyi en deruni noktadan yakalayarak; bunu düşünce, estetik zevk ve ahlakla bütünleştirmeye gayret eden bir tavrı işaret etmektedir. Öyle bir dindarlık olmalı ki; bir taraftan entelektüel bir bilinç aydınlığında ama diğer taraftan da bir iç yolculuk ve kemale doğru ahlaki bir yürüyüşs şeklinde yaşansın. Öyle bir felsefe olmalı ki; farkındalığı olan, yekdiğeriyle bütünleşen bir etkinlik halinde algılansın. 